\title{
Application of a two-dimensional code video in neurosurgery device manipulation training for growing nurses in operating room
}

\author{
Min Liu, Xuan Li, Fei Yin, Chen Yi \\ Department of Operation, Wuhan Central Hospital, Tongii Medical College, Huazhong University of Science and Technology, Wuhan, China \\ Contributions: (I) Conception and design: F Yin, M Liu; (II) Administrative support: X Li, C Yi; (III) Provision of study materials or patients: M Liu, \\ C Yi; (IV) Collection and assembly of data: F Yin, X Li, M Liu; (V) Data analysis and interpretation: F Yin, M Liu; (VI) Manuscript writing: All \\ authors; (VII) Final approval of manuscript: All authors. \\ Correspondence to: Fei Yin; Chen Yi. Department of Operation, Wuhan Central Hospital, Tongji Medical College, Huazhong University of Science \\ and Technology, Wuhan, China. Email: 11096257@qq.com; 28225369@qq.com.
}

\begin{abstract}
Background: There are many types of neurosurgery devices, their manipulation procedures are complex, and it is difficult for growing nurses in operating room to use them proficiently. In clinical practice, a set of detailed, intuitive, and flexible training methods are needed to improve the effectiveness of training for growing nurses in operating room. In this study, a two-dimensional (2D) code video was used to train growing nurses in operating room to operate these devices, aiming to improve their ability to do so in the clinical setting.
\end{abstract}

Methods: Before training, we created a video for every step of device manipulation, decoded the videos, generated a 2D code respectively, and scanned the code to play on a personal digital assistant (PDA). In 2019, we enrolled 32 growing nurses at the N1 level (N1 refers to the lowest level of nurses) in the north and south divisions of our hospital. A total of 16 nurses from the south division were trained with traditional methods, and 16 nurses from the north division were trained based on traditional training, plus 2D code video selfteaching. The intervention period for both groups was 6 months. After the intervention, the performance of the two groups was compared. Scores from the theoretical knowledge test, operation ability evaluation, and satisfaction of nurses from the training program were all compared between the two groups.

Results: The knowledge test score $(83.43 \pm 6.70$ vs. $78.60 \pm 6.08, \mathrm{P}=0.041)$ and the operation ability evaluation $(84.7 \pm 6.84$ vs. $80.93 \pm 6.59, \mathrm{P}=0.025)$ of nurses from the north division were higher than those from the south division; satisfaction of nurses from the north division was higher than that of nurses from the south division $(97.52 \pm 3.31$ vs. $93.40 \pm 5.96, \mathrm{P}=0.022)$. There were also significant differences in the total scores of study ability between the two groups $(97.87 \pm 12.37$ vs. $90.07 \pm 12.99, \mathrm{P}=0.021)$.

Conclusions: The use of a 2D code video can improve nurses' ability to manipulate neurosurgery devices.

Keywords: Two-dimensional code; video; surgical; neurosurgery device; training

Submitted Nov 23, 2020. Accepted for publication Mar 29, 2021.

doi: 10.21037 /gs-21-129

View this article at: https://dx.doi.org/10.21037/gs-21-129

\section{Introduction}

With the rapid development of neurosurgery, neurosurgery devices have evolved rapidly, resulting in a wide range of varieties, with complicated manipulation procedures. A particular type of equipment may have multiple brands and models, and the operating procedures may vary greatly.
This diversity of equipment specifics is challenging for newly enrolled growing nurses in operating room in the operating room, and adapting to these devices is often a long and complicated process (1). The skilled cooperation of growing nurses in operating room plays an important role in the process of surgery (2). It can be difficult for nurses to deftly install and use these instruments and equipment 
in a short amount of time, which affects the conduction of neurosurgery procedures. Detailed video demonstrations and simulation training can significantly improve learners' operational proficiency and shorten learning time (3). At the same time, neurosurgery is often difficult and has many emergent conditions. The requirements for the use of instruments and equipment are very high, and growing nurses in operating room are required to be highly proficient in operating the instruments and equipment. For the integration of newly introduced equipment, most hospitals currently use engineers to conduct collective training for surgeons and operating room nurses. However, it has been found that during subsequent operations, the nurses do not fully fathom the training knowledge points, which can lead to unsmooth use of the equipment and even prolong operation times (4). Traditional training involves the provision of a variety of learning materials, including flow charts and complete operation videos. However, these methods have their own shortcomings in transferring to actual use, and have a great impact on the enthusiasm and cohesive learning of nurses. In recent years, electronic media has been widely used in medical training, with good results (5). We believe that in the instance of more complicated neurosurgery instruments and equipment, nurses need more effective guidance in the training for operation. These training methods should be easy to access and imitate (6). Therefore, we designed two-dimensional (2D) code video methods, and compared operating room nurses from two divisions of our hospital to observe the effect of the 2D code video methods on nurse training.

We present the following article in accordance with the MDAR checklist (available at https://dx.doi.org/10.21037/ gs-21-129).

\section{Methods}

\section{Study population}

We used the concurrent control method to select a total of 32 growing nurses at the $\mathrm{N} 1$ level in the two divisions of our hospital in 2019, of which 16 were from the south and 16 were from the north division. This study was approved by the Ethics Committee of Wuhan Central Hospital Affiliated to Tongji Medical College of Huazhong University of Science and Technology, and all research participants provided written informed consent. All procedures performed in this study involving human participants were in accordance with the Declaration of Helsinki (as revised in 2013).

\section{Training program}

For the nurses in the south division, we used the traditional training program, which included group class, on-site demonstration, and practice, etc.; for the north division nurses, on the basis of the traditional training program, we implemented self-training based on the $2 \mathrm{D}$ code video method. For each skill, according to their own ability, the nurses were encouraged to choose the content they needed to study, scan the $2 \mathrm{D}$ code to watch the teaching video, and then imitate and practice, repeating it until proficiency was reached. The intervention period was 6 months, and afterwards, the effect of growing nurses' training was compared between the two groups.

\section{$2 D$ code video teaching}

The main steps of the $2 \mathrm{D}$ code video teaching methods were making the manipulation film, information decoding, generating 2D code, and personal digital assistant (PDA) scanning the code to play the videos. To make the manipulation film, we divided each manipulation of a certain device into several episodes (steps) and made film of each part. Then, we edited the films to make them suitable for following decoding and generation of a $2 \mathrm{D}$ code. We invited colleagues from the Information Department to help us decode the films. We then generated a specific 2D code for each episode of film and attached the printed code to the devices at easily-scanned sites. Software on the PDA (use each user name and password) was used to enter the learning interface, select specific content according to each growing nurse's own learning progress, and then scan the code to play video with illustration on the screen. The video was loaded on the PDA through the hospital's internal network, and was then played in full screen for learning purposes.

\section{Effect evaluation}

After 6 months of training for growing nurses in both divisions, the effects of training were evaluated separately. The indicators included the theoretical knowledge test score and evaluation score of device manipulation, the satisfaction of growing nurses in regards to the training, and the assessment of self-teaching ability. The theoretical knowledge test involved unified paper exam to enable 
Table 1 Comparison of baseline data between two groups of nurses in the north and south hospital divisions

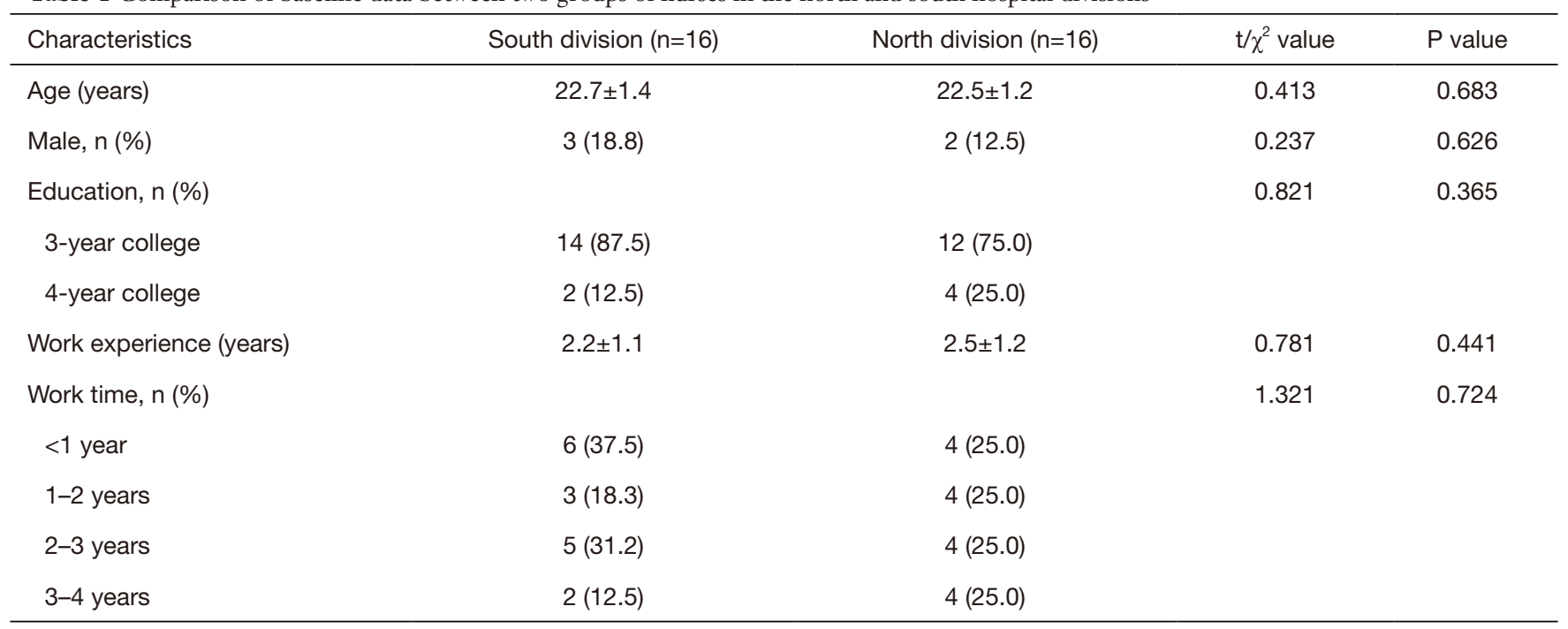

growing nurses from both divisions to take the exam at the same time, and the third-party experts who are not aware of this research scored the papers. The practical operation assessment involved a simulated operation scene, enactment of the steps of manipulation of the neurosurgery devices, and edit of items that require evaluation, which was judged and scored by third-party experts who blinded to the research details. The growing nurses' satisfaction with the training program was assessed using a self-made satisfaction questionnaire. The self-teaching ability was evaluated using the questionnaire "star self-teaching ability assessment questionnaire" (https://www.wjx.cn/jq/9873251.aspx, copyright belongs to the survey respondents, and authority was given by all survey respondents).

\section{Statistical processing}

The statistical software SPSS 23.0 (IBM Corp., Armonk, NY, USA) was used for data analysis. Quantitative data was tested for normal homogeneity. When data conformed to a normal distribution, it was described as mean \pm standard deviation, and the comparison between groups was by $t$-test; if it did not conform to a normal distribution, it was represented by the median, and the comparison between groups was made with the rank sum test. Qualitative data was expressed as a percentage, and comparisons between groups were performed by $\chi^{2}$ test. A P value $<0.05$ indicated a statistically significant difference.

\section{Results \\ Comparison of baseline characteristics of neurosurgical growing nurses in the two divisions}

A total of 32 nurses were included in this study; 16 from the south division, and 16 from the north division of our hospital. The age of participants was $21-25$ years old (22.6 \pm 1.3$) ; 5$ males (15.6\%) and 27 females (84.4\%) were included; and the level of education among the cohort included 26 associate degrees (81.2\%), and 6 bachelor degrees (18.8\%). A total of 10 participants (31.2\%) had less than 1 year of working experience, 7 had $1-2$ years (21.9\%), 9 had $2-3$ years $(28.1 \%)$, and 6 had $3-4$ years $(18.8 \%)$. The comparison of baseline characteristics between the two groups of growing nurses is shown in Table 1; no statistical difference was detected between the two groups. The production process of quick response $(\mathrm{QR})$ code videos and training flow in this study is shown in Figure 1.

\section{Comparison of theoretical knowledge test scores and evaluation score of device manipulation between two groups}

After 6 months of training, the growing nurses in the two divisions were assessed on theoretical knowledge and operational skills. The results showed that the growing nurses in the north division group had an excellent grasp of theoretical knowledge of the neurosurgery devices 


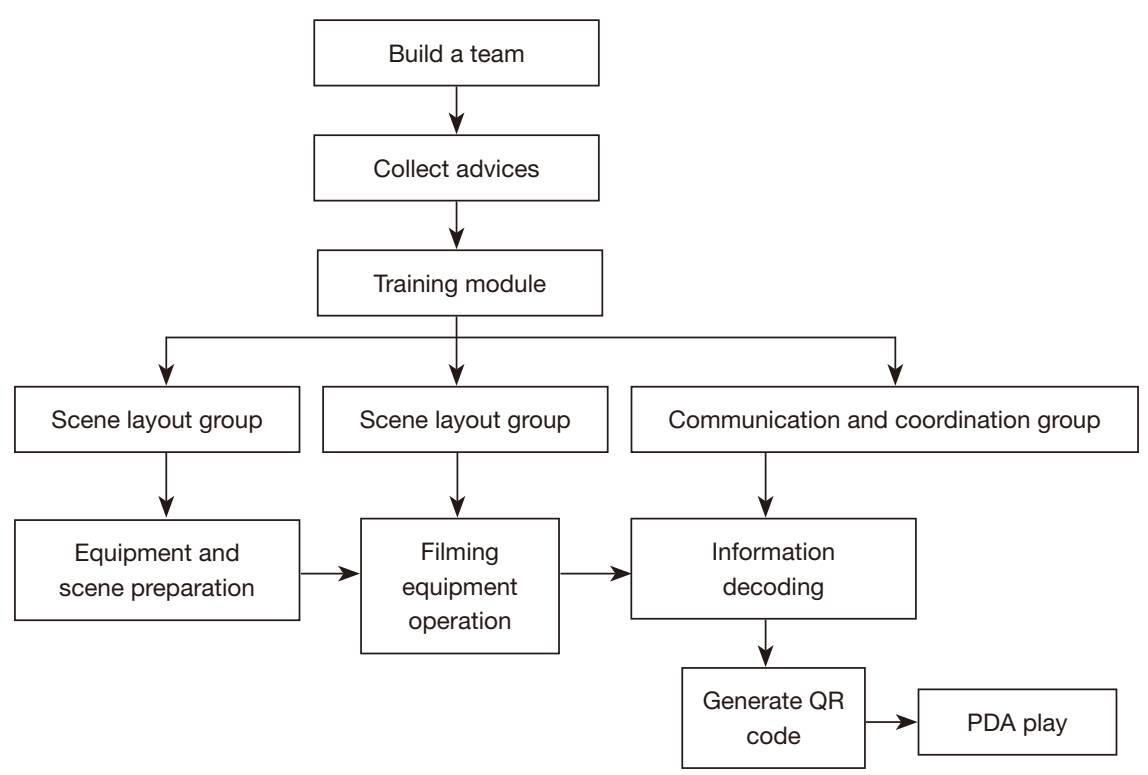

Figure 1 QR code video demonstration production process. QR, quick response; PDA, personal digital assistant.

Table 2 Comparison of theoretical knowledge test scores and evaluation score of device manipulation between two groups ( $\mathrm{n}=32, \bar{x} \pm \mathrm{s})$

\begin{tabular}{|c|c|c|c|c|}
\hline Grouping & South division $(n=16)$ & North division $(n=16)$ & $\mathrm{t}$ value & $P$ value \\
\hline Operation test score & $80.93 \pm 6.59$ & $84.70 \pm 6.84$ & 2.360 & 0.025 \\
\hline
\end{tabular}

Table 3 Satisfaction comparison of the two long-term nurses' instrument training methods ( $\mathrm{n}=32, \bar{x} \pm \mathrm{s})$

\begin{tabular}{lcccc}
\hline Score & South division $(n=16)$ & North division $(n=16)$ & $t$ value & $P$ value \\
\hline Satisfaction & $93.40 \pm 5.96$ & $97.52 \pm 3.31$ & 2.417 & 0.022 \\
\hline
\end{tabular}

compared to growing nurses in the south division, and their ability to operate equipment was also better than that of the growing nurses in the south division. The difference was statistically significant (Table 2).

\section{Comparison of the satisfaction of the two groups of growing nurses with the training program}

At the end of the training year, a satisfaction questionnaire survey was conducted on the growing nurses in both groups. The results showed that the satisfaction of growing nurses in the north division group was significantly higher than that of those in the south division group, and the difference was statistically significant (Table 3). The survey results showed that the growing nurses in the north division found the 2D code video helpful for structuring their learning flexibly according to their actual work and personal situation, thereby significantly improving training compliance.

\section{The self-teaching ability of neurosurgical growing nurses in the two divisions}

The results showed that the growing nurses in the north division had significantly improved their self-teaching ability after 6 months of training; self-management ability, information acquisition, and processing ability were significantly better compared to the south division growing 
Table 4 The self-teaching ability of neurosurgical nurses in the two divisions ( $\mathrm{n}=32, \bar{x} \pm \mathrm{s})$

\begin{tabular}{|c|c|c|c|c|c|}
\hline Time & Self-teaching ability & South division $(n=16)$ & North division $(n=16)$ & t value & $P$ value \\
\hline \multirow{3}{*}{ Before training } & Information ability & $32.83 \pm 5.98$ & $32.90 \pm 5.77$ & 0.044 & 0.965 \\
\hline & Cooperation & $21.93 \pm 4.02$ & $21.73 \pm 3.67$ & 0.201 & 0.841 \\
\hline & Total & $86.20 \pm 14.37$ & $85.97 \pm 14.39$ & 0.063 & 0.950 \\
\hline \multirow{3}{*}{ After training } & Information ability & $34.07 \pm 4.73$ & $37.03 \pm 4.48$ & 2.494 & 0.015 \\
\hline & Cooperation & $22.67 \pm 3.96$ & $24.30 \pm 3.72$ & 1.669 & 0.100 \\
\hline & Total & $90.07 \pm 12.99$ & $97.87 \pm 12.37$ & 2.382 & 0.021 \\
\hline
\end{tabular}

nurses (Table 4).

\section{Discussion}

Nurses play an important role in surgical operations and post-operative care (7-9). During complex and difficult surgical operations, the good cooperation of growing nurses plays an important role in ensuring the operation progresses smoothly, and this is especially true in neurosurgery. Doctors must concentrate on the operation itself, and the positioning and observation of instruments and equipment requires the good cooperation of growing nurses in operating room $(10,11)$; growing nurses in operating room must be proficient in the installation and use of equipment (12). In this study, by designing a $2 \mathrm{D}$ code video, the various aspects of equipment installation and operation required for neurosurgery were appropriately decomposed into multiple short videos. The 2D code link allowed growing nurses flexibility in their individual learning processes. Moreover, this method enabled growing nurses to break their learning into manageable sessions, and it was also beneficial for each nurse to select learning content according to his (or her) own ability and work arrangement. Through comparison, we found that this method significantly improved the effectiveness of neurosurgical growing nurses in training with neurosurgery instruments and equipment, and both theoretical knowledge and operating skills were significantly improved. At the same time, it also improved growing nurses' satisfaction with training and their ability to learn independently, which is conducive to promoting growing nurses' continuous learning, practice, and reducing resistance to training.

Traditional training has played an important role in clinical work and has cultivated generations of growing nurses. However, at present, medicine is developing rapidly, and various high-tech applications are increasingly used in clinical work. Nurse training programs have previously been very time consuming and growing nurses have faced difficulties in adapting to these advanced and complex equipments (13-15). Traditional training generally uses paper textbooks, flow charts posted around the workplace, and demonstration videos of the whole process. Growing nurses were traditionally trained in group classes and internships with teachers. Problems with this method include that paper-based textbooks are often too dense with words, the content is not prominent, and the explanations are not vivid and specific. The nurse has no time to properly engage with such training around their busy work schedule. Moreover, text descriptions are interpreted differently by everyone, and there may be subsequent differences in practical application of the learning. Flowcharts posted in the work area often contain small scripts, which are not convenient for reading and querying, and they cannot adequately describe details of equipment installation and operation. The demonstration video of the whole process requires extra learning and training time, involves multimedia equipment, and is often not detailed enough. Storage in a personal mobile phone consumes a lot of storage space, and it is not conducive to selecting specific content when viewing. If it is stored on a network platform and played through the network, it is limited by network conditions, which does not facilitate watching and learning anytime and anywhere near the equipment.

In the training of neurosurgery growing nurses in the operating room, the use of information-based 2D code equipment operation demonstration can teach the operating 
steps through visual and intuitive learning, minimize differences in personal understanding, and avert inconsistent or even irregular operation details. Video playback relies on the internal local area network, which means students will not incur network traffic costs. The playback tool can be a personal smart phone, or a public tablet or computer, which are easy to obtain and can be moved flexibly. The trainee can choose to focus on their less skilled areas to more efficiently improve their competency. At the same time, the details of operation can be more prominently expressed through the early video production. Through the video, the operation process can be demonstrated more clearly, and operation details can be displayed from multiple angles. Concurrently, parameters can be set through the platform to record the number of times and duration of each nurse's study, which is conducive to collating data of the nurse's performance, analysis of the nurse's learning behavior and habits, and provides a wealth of information for training optimization and management. The video production skills can also be taught to members of the specialist team. For young growing nurses, it also increases the enjoyment of learning equipment operation. The rapid development of the way information is transmitted in the operating room has greatly promoted the delegation of manpower in the operating room $(16,17)$. We can also apply informatization to our specialty management teams. In addition to using the 2D code for operation demonstration, for the actual use of neurosurgery equipment and equipment, the $2 \mathrm{D}$ code could also be used to eliminate the need to manually complete equipment registration by directly scanning the $2 \mathrm{D}$ code to complete training.

The job and vocational training satisfaction of growing nurses is of great significance to clinical work and the growing nurses' professional development and employment stability (17-19). However, the current fast-paced society, high work pressure, fierce competition, explosion of information, and continuous popularization of high-tech applications in practice have caused growing nurses to face unprecedented challenges and resistance $(20,21)$. In actual work, growing nurses, like doctors, continue to receive training while working to improve their work ability. If the training mechanism is not a good, it will inevitably cause growing nurses to resist the training, reduce the effect of training, and ultimately not promote completion of the work. If growing nurses can actively participate in the use, maintenance, and even improvement of advanced instruments and equipment, they will play a key role in promoting the development of medical devices (22-24). At present, many hospital managers attach great importance to training growing nurses to master and use medical equipment (25-27). The method of training is one of the important topics. Through exploration, this research provided a flexible, vivid, and targeted training method.

The shortcomings of this study included that it only observed the training of growing nurses in operating room on neurosurgery instruments and equipment, and therefore did not encompass equipment commonly used in other disciplines in the operating room. This method needs to be further promoted in the future throughout a broader range of specialist equipment and disciplines. The inclusion of larger samples of growing nurses in operating room from multiple medical centers in the future is necessary to conduct comparative studies, so as to further observe and continue to improve the training effect of this method. And multiple-center, randomized and controlled study is warranted in the future.

\section{Acknowledgments}

Funding: Nursing Research Grant Project of Wuhan Central Hospital in 2020 (H202009).

\section{Footnote}

Reporting Checklist: The authors have completed the MDAR checklist. Available at https://dx.doi.org/10.21037/gs-21-129

Data Sharing Statement: Available at https://dx.doi. org/10.21037/gs-21-129

Conflicts of Interest: All authors have completed the ICMJE uniform disclosure form (available at https://dx.doi. org/10.21037/gs-21-129). The authors have no conflicts of interest to declare.

Ethical Statement: The authors are accountable for all aspects of the work in ensuring that questions related to the accuracy or integrity of any part of the work are appropriately investigated and resolved. This study was approved by the Ethics Committee of Wuhan Central Hospital Affiliated to Tongji Medical College of Huazhong University of Science and Technology, and all research participants provided written informed consent. All procedures performed in this study involving human 
participants were in accordance with the Declaration of Helsinki (as revised in 2013).

Open Access Statement: This is an Open Access article distributed in accordance with the Creative Commons Attribution-NonCommercial-NoDerivs 4.0 International License (CC BY-NC-ND 4.0), which permits the noncommercial replication and distribution of the article with the strict proviso that no changes or edits are made and the original work is properly cited (including links to both the formal publication through the relevant DOI and the license). See: https://creativecommons.org/licenses/by-nc-nd/4.0/.

\section{References}

1. Uslu Y, Altınbaş Y, Özercan T, et al. The process of nurse adaptation to robotic surgery: A qualitative study. Int J Med Robot 2019;15:e1996.

2. Zarnitz P, Malone E. Surgical nurse practitioners as registered nurse first assists: the role, historical perspectives, and educational training. Mil Med 2006;171:875-8.

3. Robertson JM, Dias RD, Yule S, et al. Operating Room Team Training with Simulation: A Systematic Review. J Laparoendosc Adv Surg Tech A 2017;27:475-80.

4. Schuessler Z, Scott Stiles A, Mancuso P. Perceptions and experiences of perioperative nurses and nurse anaesthetists in robotic-assisted surgery. J Clin Nurs 2020;29:60-74.

5. Maertens H, Madani A, Landry T, et al. Systematic review of e-learning for surgical training. Br J Surg 2016;103:1428-37.

6. Flurry M, Brooke S, Micholetti B, et al. Nurse training with simulation: an innovative approach to teach complex microsurgery patient care. Ann Plast Surg 2012;69:459-61.

7. Balfour A, Burch J, Fecher-Jones I, et al. Exploring the fundamental aspects of the Enhanced Recovery After Surgery nurse's role. Nurs Stand 2019. [Epub ahead of print]. doi: 10.7748/ns.2019.e11437.

8. Qiu Y, Ouyang X, Luo M, et al. Application of a surgical nursing cooperation program in laparoscopic pancreaticoduodenectomy. Gland Surg 2020;9:1530-4.

9. Hunt L. Advanced nurse practitioners may have general surgery role. Emerg Nurse 2016;24:8-9.

10. Rimel RW, Langfitt TW. The evolving role of the nurse practitioner in neurosurgery. J Neurosurg 1980;53:802-7.

11. Harvey JE. The nurse in neurosurgery. Can Nurse 1953;49:11-8.
12. Patio C, Ali N, Ketner J, et al. Physician Assistants and Nurse Practitioners in Head and Neck Surgery. Cancer Treat Res 2018;174:17-30.

13. Fernandes MNF, Esteves RB, Teixeira CAB, et al. The present and the future of Nursing in the Brave New World. Rev Esc Enferm USP 2018;52:e03356.

14. Grant M, McCabe M, Economou D. Nurse Education and Survivorship: Building the Specialty Through Training and Program Development . Clin J Oncol Nurs 2017;21:454-9.

15. Kraus EM. An Exploratory Analysis of US Nurse Practitioner Perspectives on Training and Credentialing. Narrat Inq Bioeth 2019;9:233-46.

16. Wong HW, Forrest D, Healey A, et al. Information needs in operating room teams: what is right, what is wrong, and what is needed? Surg Endosc 2011;25:1913-20.

17. Goodhue CJ, Harris DG. Nurse Practitioner Job Satisfaction and the Healthy Work Environment. AACN Adv Crit Care Fall;30:274-7.

18. Liu J, Zhou H, Yang X. Evaluation and Improvement of the Nurse Satisfactory Status in a Tertiary Hospital using the Professional Practice Environment Scale. Med Sci Monit 2017;23:874-80.

19. Tucker SJ, Gallagher-Ford L, Baker M, et al. Promoting Nurse Retention Through Career Development Planning. Am J Nurs 2019;119:62-6.

20. Alaçam B, Altuntaş S. Career Obstacles Faced by Female Nurse Academicians in Turkey. J Nurs Res 2017;25:353-60.

21. Halperin O, Mashiach-Eizenberg M. Becoming a nurse - A study of career choice and professional adaptation among Israeli Jewish and Arab nursing students: A quantitative research study. Nurse Educ Today 2014;34:1330-4.

22. Glasgow MES, Colbert A, Viator J, et al. The NurseEngineer: A New Role to Improve Nurse Technology Interface and Patient Care Device Innovations. J Nurs Scholarsh 2018;50:601-11.

23. Lucero RJ, Ji H, de Cordova PB, et al. Information technology, nurse staffing, and patient needs. Nurs Econ 2011;29:189-94.

24. Weir H, Grocott P, Ram MB. The nurse's role in contributing to new device development. Nurs Times 2006;102:36-9.

25. McConnell EA, Fletcher J. Australian registered nurse medical device education: a comparison of lifesustaining and non-life-sustaining devices. J Adv Nurs 1993;18:1586-94.

26. Douglas MR, Leigh JA, Douglas CH. UK registered nurse 
medical device education: a comparison of hospital and bank nurses. Nurse Educ Pract 2001;1:85-93.

27. Hilbig JI. The operating room registered nurse: medical device training needs and current practice in Australia.

Cite this article as: $\mathrm{Liu} \mathrm{M,} \mathrm{Li} \mathrm{X,} \mathrm{Yin} \mathrm{F,} \mathrm{Yi} \mathrm{C.} \mathrm{Application}$ of a two-dimensional code video in neurosurgery device manipulation training for growing nurses in operating room. Gland Surg 2021;10(12):3233-3240. doi: 10.21037/gs-21-129
Biomed Instrum Technol 1998;32:25-31.

(English Language Editor: J. Jones) 